\title{
Climatic selection on body colour in the land snail Theba pisana (Pulmonata: Helicidae)
}

\author{
Robert H. Cowie
}

Bernice P. Bishop Museum, P.O. Box 19000A, Honolulu, Hawaii 96817, U.S.A.

Eighty-one samples of the land snail Theba pisana were collected from 34 localities throughout its natural Mediterranean, western European and north African coastal distribution and from introduced populations in Western Australia and California. The colour intensity (a score of relative darkness) of the mantle collar, which is visible while the snail is retracted into its shell, was scored by matching to a colour atlas. Despite much within-population variation, among-population variation was significantly related to mean daily maximum temperature of the hottest month, as recorded at nearby meteorological stations. Climatic selection favouring pale colour in hot places is probably responsible for the association.

\section{INTRODUCTION}

In many animals, individuals from hotter climates are paler than those from cooler parts of the species' range. A frequent explanation is that natural selection in hot places favours a pale coat, skin, shell, etc. to reflect sunlight and to help the animal maintain a lower body temperature. In cool places a dark colour, which absorbs more solar energy, is favoured as it enables the animal to reach its operating temperature more quickly, if poikilothermic, and/or to maintain body temperature with less energy expenditure. Clearly, other factors, particularly the need for camouflage, may over-ride such climatic selection, both throughout the species' range or more locally.

The European land snail Cepaea is perhaps the classic example in which the mechanisms governing genetically controlled colour variation in natural populations have been studied (Cain, 1983; Cameron and Dillon, 1984; Jones, Leith and Rawlings, 1977). Populations in hotter regions tend to have higher frequencies of pale shells (Jones, Leith and Rawlings, 1977) and climatic selection is one mechanism involved in this (Heath, 1975; Richardson, 1974). Body colour, which is continuously variable, shows a similar pattern (Cowie and Jones, 1985).

A preliminary survey of geographic variation in body colour in the land snail Theba pisana (which is found throughout coastal areas of the Mediterranean, extending along the Atlantic coasts of Europe and north Africa, and which has been introduced accidentally to Australia, South Africa and California) suggested that climatic selection was involved in producing the differences among populations (Cowie, 1983). This observation is extended here with the inclusion of further data sufficient to allow statistical analysis.

\section{METHODS}

Eighty-one samples from 34 localities (fig. 1, table 1) were obtained between 1977 and 1989 (including those of Cowie, 1983). Each was taken from as small an area as possible. At least 30 snails-but often many more-could usually be obtained from a single site of no more than $25 \mathrm{~m}^{2}$ and frequently from less than $1 \mathrm{~m}^{2}$. Once a site had been demarcated, all snails were collected from within it.

Mantle collar colour, the most variable part of the body, was scored as by Cowie (1983), using a colour atlas (Villalobos-Dominguez and Villalobos, 1947). Only colour intensity is analysed here, providing a measure of darkness ranging from black $(0)$ to white $(20)$. Only snails larger than $10.0 \mathrm{~mm}$ in shell diameter were scored (total 4009 snails) since mantle collar colour darkens with increasing shell size (Cowie, 1983). 


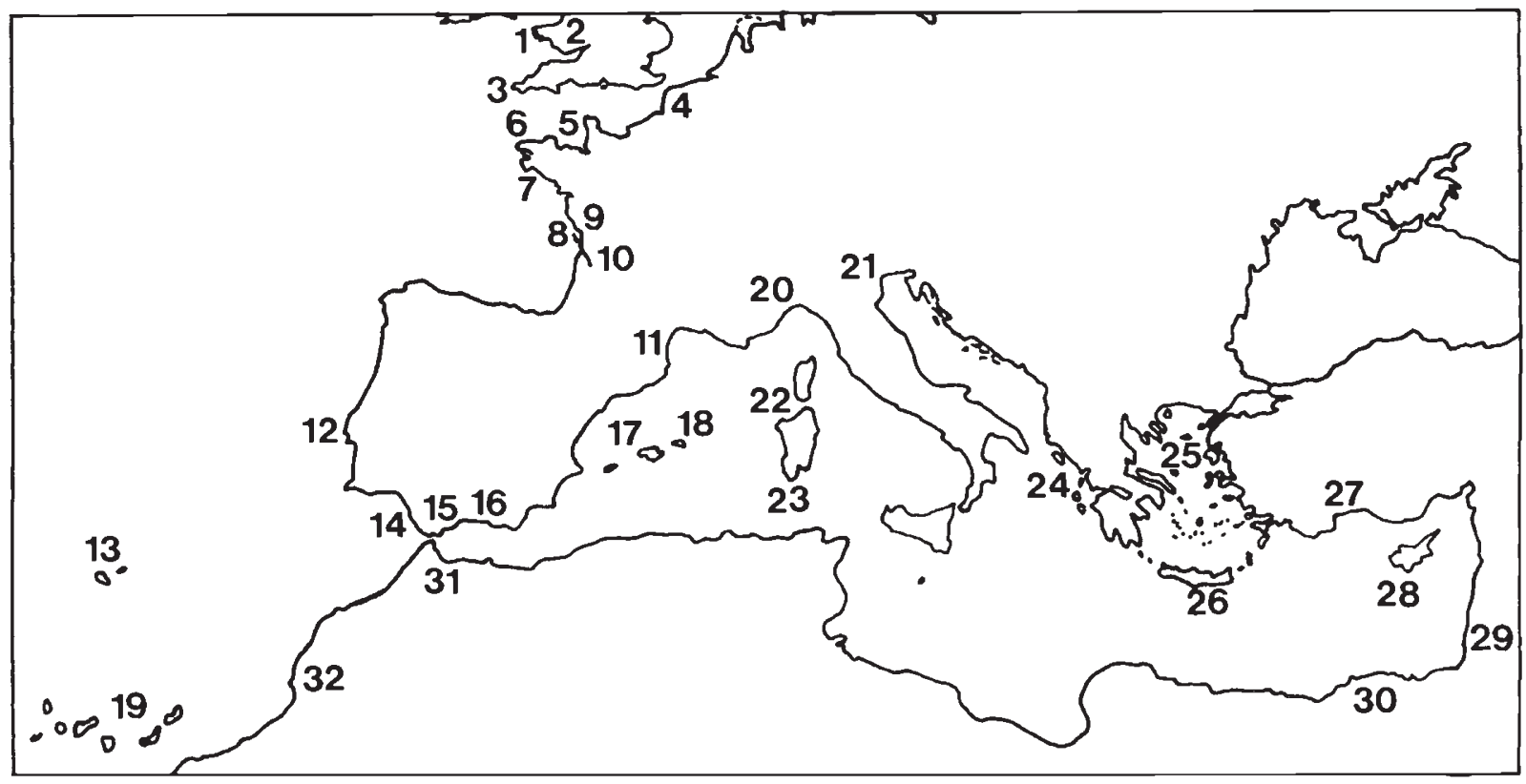

Figure 1 Map showing sampling localities, excluding Western Australia and California, numbered as in table 1.

Climatic data representative of each sampling locality were obtained from publications of the Meteorological Office (1972, 1975, 1976, 1980, 1983) using the closest appropriate meteorological stations. Some samples, taken close together, were represented only by a single meteorological station; colour data were then combined as the mean of the individual sample means. In only one case (Ashqelon, Israel) was a station more than $75 \mathrm{~km}$ from a sample site and in only seven of the 34 sites was it more than $50 \mathrm{~km}$ away.

Mean colour score for each locality was regressed on mean daily maximum temperature of the month with the highest mean daily maximum, which is probably the most important readily available measure of temperature for snail thermal relations and climatic selection ( $\mathrm{cf}$. mean daily maximum temperature for July-Cowie and Jones, 1985; mean daily temperature-Jones, Leith and Rawlings, 1977).

\section{RESULTS}

Individual scores ranged from 0 to 18 , black to a pale off-white. Mean sample scores ranged from zero to $17 \cdot 33$ and, after combining some samples as indicated above, mean scores for each locality ranged from 0.29 to 14.76 (table 1 ). Most samples were large enough that it was not necessary to weight scores according to sample size in order to carry out the regression analysis (fig. 2). The single exceptionally small sample (Alghero, Sardinia) is indicated in fig. 2.

The linear regression of colour score $(C)$ on temperature $\left(T\right.$ in $\left.{ }^{\circ} \mathrm{C}\right)$ is significant $\left(r^{2}=0 \cdot 268\right.$, $P=0.0017)$ and given by:

$$
C=-3 \cdot 85+0 \cdot 38 T \text {. }
$$

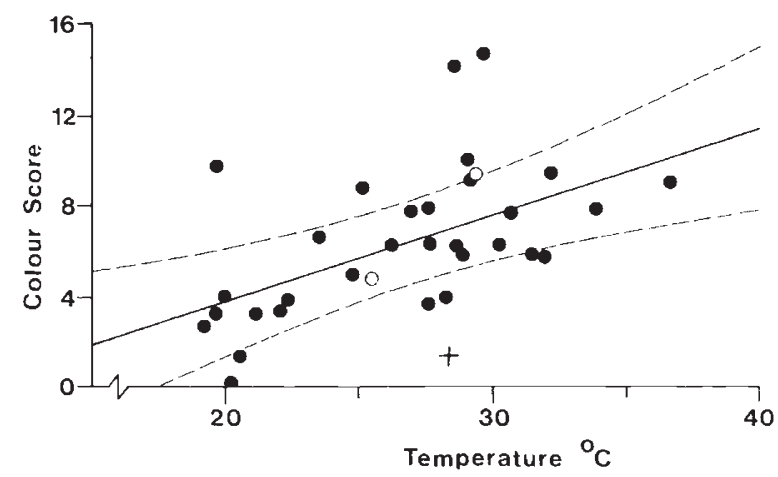

Figure 2 Regression of mean mantle collar colour score from each locality on mean daily maximum temperature of the hottest month. (The cross represents the sample from Alghero; the open circles represent the samples from the introduced populations in California and Australia; the dashed lines represent 95 per cent confidence limits of the regression). 
Table 1 Mean colour intensity scores, with standard deviation if based on a single sample, and number of snails scored for samples of Theba pisana, with mean daily maximum temperature of the hottest month $(\mathrm{J}=\mathrm{July}, \mathrm{A}=\mathrm{August}, \mathrm{S}=\mathrm{September}, \mathrm{Ja}=\mathrm{J}$ anuary, $\mathrm{F}=$ February) at the nearest appropriate meteorological station to the sample site and for which data are available in the publications of the Meteorological Office $(1972,1975,1976,1980,1983)$. Where samples have been combined for a given area, the number of samples is given in parentheses.

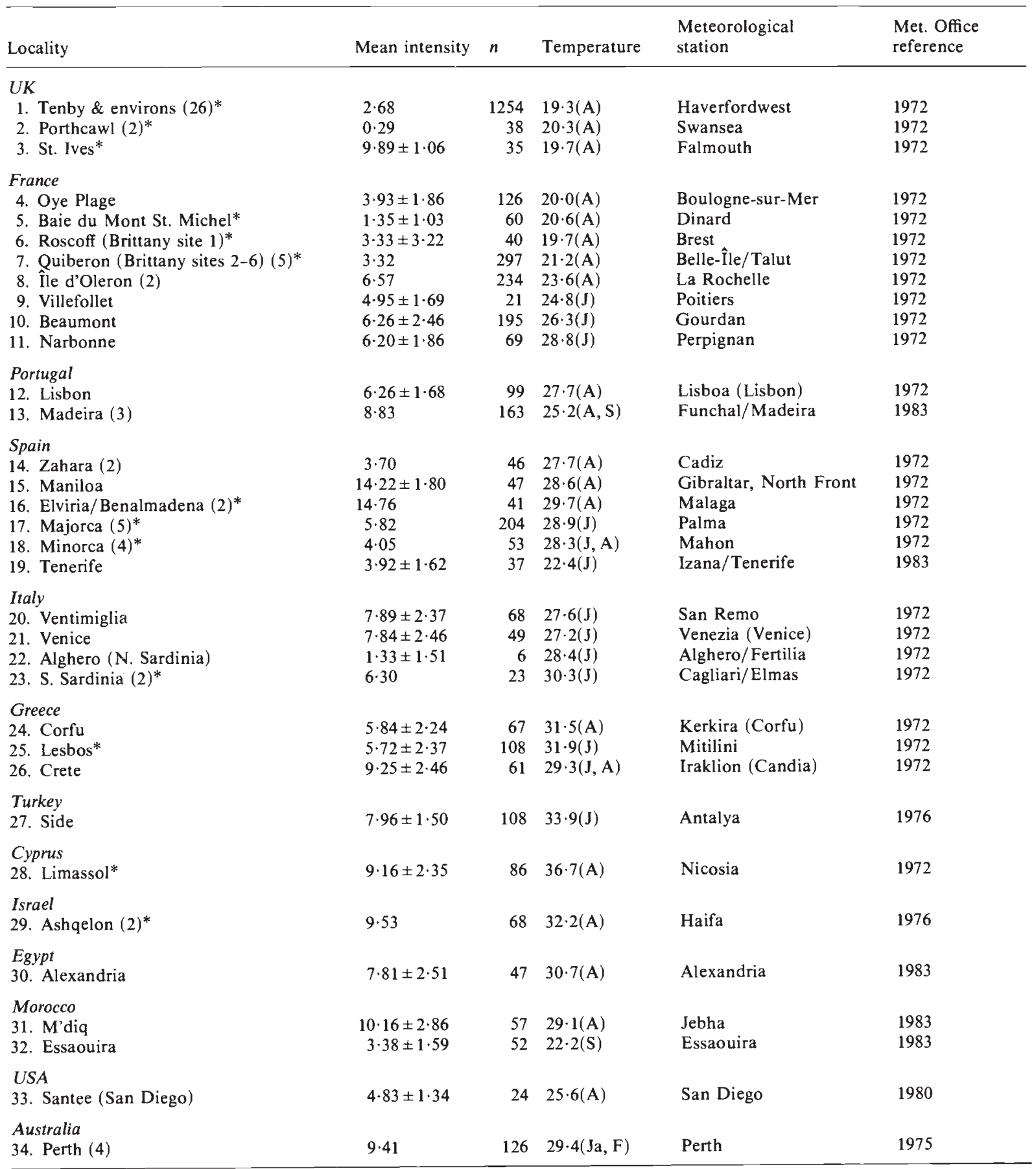

* Samples used by Cowie (1983) 
This includes the two localities with introduced populations (Perth, Australia and Santee, California). If these are excluded, the regression is still highly significant $\left(r^{2}=0.259, P=0.0029\right)$ and given by:

$$
C=-3 \cdot 61+0 \cdot 37 T \text {. }
$$

There is, therefore, a strong association between pale mantle collar colour and a hot climate.

\section{DISCUSSION}

Body colour in T. pisana, as in Cepaea and other land snails, is likely to be at least partially under genetic control, although for $T$. pisana this has not been demonstrated experimentally (Cowie, 1983). Climate and predators are the predominant selective agents influencing both shell and body colour variation in Cepaea (Cain, 1983; Cowie and Jones, 1985; Jones, Leith and Rawlings, 1977); both have been implicated in the maintenance of shell pattern variation in $T$. pisana (Heller, 1981; Johnson, 1981), the genetic control of which is partially understood (Cain, 1984; Cowie, 1984). The present study indicates that climatic selection is also the most likely mechanism maintaining the broad relation between mantle collar colour and temperature in T. pisana.

It is unlikely that climatic or visual selection operate when the snails are active, since the variation might then be expected to include the extruded head/foot, which it does not, this being generally fairly pale. T. pisana is largely nocturnal, resting during the day attached above ground to vegetation. Selection on the mantle collar colour could then operate when the snails attach themselves to thin stems, which they frequently do, secreting either a thin transparent epiphragm, or none at all, over the aperture so that the mantle collar remains exposed. Visual selection would not produce the large-scale geographic trend seen here, unless there were a similar trend in background vegetation/substrate colour, and there is no obvious evidence of this. Visual selection may well be significant locally and may then over-ride the general trend due to climatic selection, as for shell pattern variation in $T$. pisana in Israel (Heller, 1981; Heller and Gadot, 1984). As in Cepaea (Cowie and Jones, 1985; Jones, Leith and Rawlings, 1977), the balance among these and other factors will differ from place to place, producing the wide scatter around the regression of colour on temperature (fig. 2).
Acknowledgements I thank A. J. Cain for discussion and both him and J. S. Jones for comments on the manuscript. This work was begun at Liverpool University and continued, in part, at University College London; I thank both institutions for the facilities provided. I am grateful to the many people who collected samples for me, assisted in my own collecting or provided hospitality.

\section{REFERENCES}

CAIN, A. J. 1983. Ecology and ecogenetics of terrestrial molluscan populations. In Russel-Hunter, W. D. (ed.) The Mollusca. Vol. 6, Academic Press, London, pp. 597-647.

CAIN, A. J. 1984. Genetics of some morphs in the land snail Theba pisana. Malacologia, 25, 381-411.

CAMERON, R. A. D. AND DILlON, P. J. 1984. Habitat stability, population histories and patterns of variation in Cepaea. Malacologia, 25, 271-290.

COWIE, R. H. 1983. Variation in mantle collar colour in the land snail Theba pisana: evidence of climatic selection? Proc. Acad. Nat. Sci. Philad., 135, 154-162.

COWIE, R. H. 1984. Ecogenetics of Theba pisana (Pulmonata: Helicidae) at the northern edge of its range. Malacologia, $25,361-380$.

COWIE, R. H. AND JONES, J. S. 1985. Climatic selection on body colour in Cepaea. Heredity, 55, 261-267.

HEATH, D. J. 1975. Colour, sunlight and internal temperatures in the land-snail Cepaea nemoralis (L.) Oecologia, 19, 2938.

HELLER, J. 1981. Visual versus climatic selection of shell banding in the landsnail Theba pisana in Israel. J. Zool., Lond., 194, 85-101.

HELLER, J. AND GADOT, M. 1984. Shell polymorphism of Theba pisana-the effects of rodent distribution. Malacologia, 25 , 349-354.

JOHNSON, M. S. 1981. Effects of migration and habitat choice on shell banding frequencies in Theba pisana at a habitat boundary. Heredity, 47, 121-133.

JONES, J. S., LEITH, B. H. AND RAWLINGS, P. 1977. Polymorphism in Cepaea: a problem with too many solutions? Ann. Rev. Ecol. System., 8, 109-143.

METEOROLOGICAL OFFICE 1972. Tables of temperature, relative humidity, precipitation and sunshine for the world. Part III, Europe and the Azores. H.M.S.O., London.

METEOROLOGICAL OFFICE 1975. Tables of temperature, relative humidity and precipitation for the world. Part VI. Australia and the south Pacific Ocean. H.M.S.O., London.

METEOROLOGICAL OFFICE 1976. Tables of temperature, relative humidity and precipitation for the world. Part V. Asia. H.M.S.O., London.

METEOROLOGICAL OFFICE 1980. Tables of temperature, relative humidity, precipitation and sunshine for the world. Part I. North America and Greenland (including Hawaii and Bermuda). H.M.S.O., London.

METEOROLOGICAL OFFICE 1983. Tables of temperature, relative humidity, precipitation and sunshine for the world. Part $I V$. Africa, the Atlantic Ocean south of $35^{\circ} \mathrm{N}$ and the Indian Ocean. H.M.S.O., London.

RICHARDSON, A. M. M. 1974. Differential climatic selection in natural populations of land snail Cepaea nemoralis. Nature, 247, 572-573.

VILLALOBOS-DOMINGUEZ, C. AND VILlALOBOS, J. 1947. Colour Atlas. Libreria el Ateneo Editorial, Buenos Aires. 